\title{
Enhancing Hepatic Fatty Acid Oxidation as a Strategy for Reversing Metabolic Disorders Programmed by Maternal Undernutrition During Gestation
}

\author{
Juana María Torrensa Josep M. Orellana-Gavaldàb Mariona Palou ${ }^{a} \quad$ Juana Sánchez ${ }^{\mathrm{a}}$ \\ Laura Herrero $^{b}$ Catalina Picóa Dolors Serra ${ }^{b}$ Andreu Palou ${ }^{a}$ \\ aLaboratory of Molecular Biology, Nutrition, and Biotechnology (Nutrigenomics), University of the \\ Balearic Islands and CIBER Fisiopatología de la Obesidad y Nutrición (CIBEROBN), Palma de Mallorca, \\ Balearic Islands, bDepartment of Biochemistry and Molecular Biology, Facultat de Farmàcia, Universitat \\ de Barcelona; Institut de Biomedicina de la Universitat de Barcelona (IBUB); and CIBER Fisiopatología \\ de la Obesidad y Nutrición (CIBEROBN), Barcelona, Spain
}

\section{Key Words}

Cpt1a $\bullet$ Calorie restriction $\cdot$ Gestation $\bullet$ Gene transference $\bullet$ Liver

\begin{abstract}
Background/Aims: Moderate maternal calorie-restriction during gestation programmes offspring for a major propensity to develop metabolic alterations in adulthood. We aimed to assess whether increased hepatic fatty-acid oxidation (FAO), at early ages, by gene transfer of Cpt1am (active mutant of carnitine palmitoyltransferase-1a), may be a strategy for reversing metabolic disturbances associated to maternal calorie-restriction during gestation in rats. Methods: AAV-Gfp (control) and AAV-CptIam vectors were administered by tail vein injection in 18-day-old control-pups and the offspring of $20 \%$ calorie-restricted rats during gestation (CR). After weaning, animals were fed with normal-fat diet. At the age of 4 months, they were moved to HF-diet and sacrificed at the age of 6 months to collect tissues. Locomotive activity, energy expenditure and blood pressure were measured. Results: Under HF-diet, CRanimals showed higher HOMA-IR, adipocyte diameter and hepatic triglyceride accumulation than controls; these alterations were reverted in CptIam-injected animals. In liver, this treatment ameliorated inflammatory state, decreased expression of lipogenesis-related genes and partially restored the decreased expression of leptin-receptor occurring in CR-animals. Treatment also reverted the decreased energy expenditure and the increased blood pressure of CR-animals. Conclusion: Increasing hepatic FAO through AAV-CptIam injection at juvenile ages prevents some metabolic disorders associated to gestational maternal calorie-restriction.
\end{abstract}

Copyright $@ 2014$ S. Karger AG, Basel 


\section{Introduction}

Obesity prevalence is increasing worldwide and hence the risk for related chronic diseases such as insulin resistance, type 2 diabetes, dyslipidemia, cardiovascular diseases, hypertension and nonalcoholic fatty liver disease (NAFLD) [1]. Besides the contribution of genetic and environmental factors, growing evidence links nutritional and other environmental conditions during early life to the subsequent development of obesity and other features of the metabolic syndrome [2,3]. Development of new strategies to prevent or treat obesity and its related metabolic disorders by reverting metabolic programming may be of interest.

Gestation is a critical period of development, and food restriction during this stage has been described to induce permanent metabolic changes in the offspring increasing the propensity to obesity and related risk parameters in adult life [4]. In this regard, we have previously shown that moderate $(20 \%)$ calorie restriction in rats during the first half of gestation programmes the offspring for a lower capacity to respond to insulin and to central leptin action and results in higher food intake in adulthood [5, 6]. Male offspring show higher and earlier harmful effects than females, while females appear more resistant to the detrimental effects of gestational calorie restriction, in terms of maintenance of body weight [6].

Bearing in mind that the ultimate cause of obesity is an imbalance between energy intake and expenditure, strategies enabling the energy balance to be inclined towards fattyacid oxidation (FAO) could improve obesity-related disorders. In fact, chronic increased hepatic FAO through adeno-associated virus (AAV)-mediated gene transfer of the key gene for mitochondrial $\beta$-oxidation, carnitine palmitoyltransferase 1 a $(C p t 1 a)$, or to a better extent Cpt1am, a permanently active form of CPT1A insensitive to its physiological inhibitor malonyl-CoA, have been shown to reduce high-fat (HF) diet-induced hepatic steatosis, weight gain, inflammation, diabetes and insulin resistance in mice [7]. Genetically obese $d b / d b$ mice expressing Cpt1am also show lower glucose and insulin levels and reduced liver steatosis [7]. Short-term studies that increase FAO in liver by genetic transfer of Cpt1a also show a decrease in hepatic triglyceride (TG) content in obese rats [8]. Therefore, increased hepatic FAO in adult animals by overexpression of Cpt1a has been proposed as a new potential therapeutic target against obesity-induced disorders [7, 8].

Considering that offspring of $20 \%$ calorie restricted dams is an animal model with a major propensity to suffer obesity, hyperinsulinemia and leptin resistance $[5,6]$, here we aimed to assess whether increased hepatic FAO at early ages of life through AAV-mediated gene transfer of Cpt1am may be a strategy to trigger a persistent reversion of metabolic disturbances related to developmental malprogramming.

\section{Methods and Materials}

\section{Adeno-associated vectors}

AAV vectors serotype 1, AAV1-AAT-Gfp and AAV1-AAT-Cpt1am, driving mouse liver expression of green fluorescence protein ( $G f p$ ) and $C p t 1 a m$, respectively, were used. Details of these constructs are described in [7]. Briefly, vector plasmids carried human albumin enhancer element, human 1-antitrypsin (EalbAATp) liver-specific promoter, the cDNA sequence of Gfp and Cpt1am, woodchuck posttranscriptional regulatory element (WPRE, Access. No.AY468-486) and bovine growth hormone polyadenosine transcription termination signal [bGHpoly(A)] (bases 2326-2533 GenBank Access. No.M57764). The expression cassette was flanked by two inverted terminal repeats (ITRs) derived from AAV2. AAV1 vectors were produced in insect cells using baculovirus. The vector preparations used had titers of $1 \times 10^{12}$ and $7.5 \times 10^{11}$ genome copies (gc)/ml for AAV1-AAT-Gfp and AAV1-AAT-Cpt1am, respectively. 


\section{Animals and Experimental Design}

The animal protocol followed in this study was reviewed and approved by the Bioethical Committee of the University of the Balearic Islands and guidelines for the use and care of laboratory animals of the University were followed.

The study was conducted on male Wistar rats from 16 different litters following the protocol as is described below. The study was performed with male animals because they have been shown to be more sensitive to the effects of maternal undernutrition during gestation compared to females, concerning features of the metabolic syndrome $[5,6]$.

Animals were housed under standard conditions, that is, controlled temperature $\left(22^{\circ} \mathrm{C}\right)$, a $12 \mathrm{~h}$ lightdark cycle and free access to tap water. 16 virgin female Wistar rats weighing between $220 \mathrm{~g}$ and $250 \mathrm{~g}$ were mated with male rats (Charles River Laboratories, Barcelona, Spain). Day of conception (day 0 of pregnancy) was determined by examination of vaginal smears for the presence of sperm, and then female rats were single caged. Pregnant rats were divided into either control $(n=7$ dams) or calorie restricted $(n=9$ dams) groups. Control dams had free access to standard chow diet (3kcal/g, with $8 \%$ calories from fat; Panlab, Barcelona, Spain), while calorie restricted (CR) dams underwent $20 \%$ restriction of calorie intake from day 1 to day 12 of pregnancy. Calorie restriction was performed by offering each dam a daily amount of food corresponding to $80 \%$ of the calories they should be eaten according to body weight. This amount was calculated by considering the calories consumed daily by their control animals under ad libitum feeding conditions. After the calorie restriction period, rats were allowed to eat ad libitum. At day 1 after delivery, pups were weighed and the size of all litters was adjusted to 10 neonates per dam (five males and five females, when possible). During the lactating period, control and CR dams had unlimited access to standard chow diet. Body weight and food intake of both control and CR dams were measured throughout the whole periods of gestation and lactation.

At the age of 18 days, AAV1 vectors were administered by tail vein injection in control $(n=21)$ and $C R$ $(\mathrm{n}=19)$ male pups in a single dose of $7.5 \times 10^{12}$ genome copies/kg of body weight, as described [7]. Before treatment, pups were anesthetized with isofluorane. Half of the male control and CR pups were injected with the control construct (AAV-Gfp), and referred to as C-C and CR-C, respectively. The other half of pups were injected with AAV1 vectors carrying the cDNA for Cpt1am (AAV-Cpt1am), and referred to as C-CPT and CR-CPT, respectively. After injections, pups were returned to their respective dams.

All pups were weaned at 21 days of life, and then housed one per cage and fed on a normal-fat (NF) standard chow diet (3.8kcal/g, with 10\% calories from fat; Research Diets, NJ, ScholarOne, 375 Greenbrier Drive, Charlottesville, VA, 22901 USA) until the age of 4 months. Then, all animals were exposed to HF diet ( $4.7 \mathrm{kcal} / \mathrm{g}$, with $45 \%$ calories from fat; Research Diets, Inc., NJ, USA) until the age of 6 months. HF diet contained 5.5\% calories from soybean oil and 39.5\% from lard. Body weight and food intake of the offspring were recorded from weaning until the age of 6 months, when animals were killed. Locomotive activity and energy expenditure were measured at the age of 3 months by indirect calorimetry. Blood pressure was also measured at the age of 5 months. Two weeks before sacrifice, blood samples of all animals were collected after $12 \mathrm{~h}$ fasting from the saphenous vein. Plasma was obtained as described above to analyze circulating parameters. Finally, at the age of 6 months, the four groups of animals were killed under ad libitum feeding conditions by decapitation during the first $2 \mathrm{~h}$ at the beginning of the light cycle and on different consecutive days. At killing, the liver and retroperitoneal white adipose tissue (rWAT) were rapidly removed and weighed. A part of the two tissues was immediately frozen in liquid nitrogen and stored at $-80^{\circ} \mathrm{C}$ until analysis. Another part of the liver was immediately homogenised to isolate mitochondria. Finally, pieces of liver and rWAT were collected for histological analysis. To avoid adipocyte and hepatocyte damage, and to preserve the integrity of their respective membranes, liver and rWAT samples were immediately fixed by immersion in $4 \%$ paraformaldehyde in $0.1 \mathrm{M}$ phosphate buffer $(\mathrm{pH}=7.4)$ at $4^{\circ} \mathrm{C}$ for $24 \mathrm{~h}$. Then, fixed samples were washed and stored in $0.1 \mathrm{M}$ phosphate buffer $(\mathrm{pH}=7.4)$ until subsequent analysis. Trunk blood samples were also collected in heparinized containers. Plasma was obtained by centrifugation of heparinized blood at $1000 \mathrm{xg}$ for $10 \mathrm{~min}$ and stored at $-20^{\circ} \mathrm{C}$ until analysis of circulating parameters.

\section{GFP detection in hepatocytes}

The presence of GFP was examined in hepatocytes of animals injected with the AAV-Gfp vector by using a confocal laser scanning microscope. To prepare samples, pieces of frozen liver were fixed by immersion in $4 \%$ paraformaldehyde in $0.1 \mathrm{M}$ phosphate buffer $(\mathrm{pH}=7.4)$ at $4^{\circ} \mathrm{C}$ for $24 \mathrm{~h}$, and washed in $0.1 \mathrm{M}$ 
phosphate buffer $(\mathrm{pH}=7.4)$ for $24 \mathrm{~h}$. Then, samples were immersed in $30 \%$ sucrose in PBS buffer $1 \mathrm{x}$ for $72 \mathrm{~h}$ at $4^{\circ} \mathrm{C}$. Before sectioning, the microtome chamber of the cryostat (Microtome cryostat HM $505 \mathrm{E}$, Microm International $\mathrm{GmbH}$, Walldorf, Germany) was set at $-25^{\circ} \mathrm{C}$ (optimal cutting temperature for liver) for $24 \mathrm{~h}$. Finally, tissues were embedded in 0.C.T ${ }^{\mathrm{TM}}$ compound (Sakura Finetek, The Netherlands) on the specimen stage and put into the fast freezing station for $24 \mathrm{~h}$. Fifteen micrometer-thick sections of tissues were cut and mounted on slides. Liver sections were washed in PBS buffer $1 \mathrm{x}$ and hepatocyte nuclei were stained with blue-fluorescence DAPI dilactate 300nM in PBS buffer (Life Technologies S.A., Madrid, Spain) according to the manufacturer's instructions. Finally, slides were mounted with Dako Fluorescence Mounting Medium (Dako Diagnostics, S.A. Barcelona, Spain), cover-slipped and protected from light. Microscopic examinations were conducted with an automated inverted microscope DMI 4000B coupled with Leica TCS SPE Confocal Laser System (Leica Microsystems S.L.U., Barcelona, Spain). The fluorescence spectral properties selected were: for DAPI, $405 \mathrm{~nm}$ excitation maximum and emission spectral range from 418 to $468 \mathrm{~nm}$; for GFP, $488 \mathrm{~nm}$ excitation maximum and emission spectral range from 500 to $550 \mathrm{~nm}$. Digital images were acquired by scanning with the fluorescence spectral properties described above and the projections of the individual channels were merged in Leica Application Suite Software 2.3.6 to facilitate visualization.

\section{Isolation of mitochondria from liver}

Mitochondria from liver samples were isolated as previously described [7] with minor modifications. Briefly, 2g of liver obtained from 6-month-old animals at sacrifice were immediately homogenized in $20 \mathrm{~mL}$ of a buffer solution (70mM sucrose, $220 \mathrm{mM}$ mannitol, $2 \mathrm{mM}$ EDTA, $5 \mathrm{mM}$ HEPES and protease inhibitor cocktail from Roche, $\mathrm{pH}=7.4$ ) by using a glass homogenizer Potter-Elvehjem, and centrifuged at $600 \mathrm{x} \mathrm{g}$ for $15 \mathrm{~min}$ at $4^{\circ} \mathrm{C}$. The supernatant was centrifuged again at $12000 \mathrm{xg}$ for $20 \mathrm{~min}$ at $4^{\circ} \mathrm{C}$. The pellet was resuspended in $2 \mathrm{~mL}$ of buffer solution and centrifuged at $7000 \mathrm{xg}$ for $10 \mathrm{~min}$ at $4^{\circ} \mathrm{C}$. Finally, the mitochondrial-enriched pellet was resuspended in $1 \mathrm{~mL}$ of buffer solution and stored at $-80^{\circ} \mathrm{C}$ until used for Western blot analysis.

\section{Western blot analysis}

Western blot was performed to determine CPT1A, total AKT (serine/threonine protein kinase) and phosphorylated AKT on Serine 473 (pAKT) in homogenates of the whole liver and of CPT1A in homogenates of the hepatic mitochondrial fraction of the animals at the age of 6 months.

Liver was homogenized at $4^{\circ} \mathrm{C}$ in 1:10 (w:v) of RIPA lysis buffer $1 \mathrm{x}$ (1M Tris $\mathrm{HCl}$ buffer $\mathrm{pH}=7.4$, containing $1 \mathrm{M} \mathrm{NaCl}, 10 \%$ deoxycholic acid, 10\% NP40 and 0.5M EDTA) with protease and phosphatase inhibitor cocktail (Halt ${ }^{\mathrm{TM}}$ Protease \& Phosphatase Inhibitor Cocktail 100x, Thermo Fisher Scientific Inc, Madrid, Spain). The homogenate was centrifuged at $7500 \mathrm{x} \mathrm{g}$ for $2 \mathrm{~min}$ at $4^{\circ} \mathrm{C}$, and the supernatant was used for protein analysis. Total hepatic protein content was measured with the Pierce BCA protein assay kit (Thermo Scientific, Rockford. U.S.A). For analysis, $60 \mu \mathrm{g}$ (for CPT1A) or 50 $\mu \mathrm{g}$ (for total AKT and pAKT) of total protein was solubilized and boiled for $3 \mathrm{~min}$ in Laemmli sample buffer containing $5 \% 2$ - $\beta$-mercaptoethanol. Then, total protein was fractionated by using a $4-15 \%$ precast polyacrylamide gel $\left(\right.$ Criterion $^{\mathrm{TM}} \mathrm{TGX}^{\mathrm{TM}}$, Bio-Rad Laboratories, Inc, U.S.A) with a standard Tris-glycine running buffer system and subsequently electrotransferred onto a $0.2 \mu \mathrm{m}$ nitrocellulose membrane (Bio-Rad, Madrid, Spain). To electrotransfer, a Trans-blot Turbo Transfer System was used, following the manufacture's instructions (Bio-Rad, Madrid, Spain). After blocking, the membrane was incubated with primary rabbit polyclonal anti-CPT1A antibody (Santa Cruz Biotechnology, Inc., CA, USA) diluted 1:1000 or anti-total AKT antibody (Cell Signalling Technology, Inc., Danvers, MA) diluted 1:2000, and then with secondary goat anti-rabbit antibody infrared (IR)-dyed-800 (LI-COR Biociences, Nebraska, USA) diluted 1:25000. For pAKT analysis, the membrane was incubated with primary mouse polyclonal anti-pAKT (Cell Signalling Technology, Inc., Danvers, MA) diluted 1:2000, and then with secondary goat anti-mouse antibody infrared (IR)-dyed-680 (LI-COR Biociences, Nebraska, USA) diluted 1:25000. For IR detection, membranes were scanned in Odyssey Infrared Imaging System (LI-COR Biociences, NE, USA), and the bands were quantified using the analysis software provided (Odyssey Software V.3.0). $\beta$-Actin was used as a housekeeping protein.

CPT1A was also determined in the hepatic mitochondrial fraction. Mitochondria were precipitated from the mitochondrial-enriched pellet in buffer solution by centrifuging at $7000 \mathrm{xg}$ for $10 \mathrm{~min}$ at $4^{\circ} \mathrm{C}$. The pellet was sonicated at $4^{\circ} \mathrm{C}$ in $150 \mu \mathrm{l}$ of cellular PBS buffer with protease and phosphatase inhibitor cocktail (Halt ${ }^{\mathrm{TM}}$ Protease \& Phosphatase Inhibitor Cocktail 100x, Thermo Fisher Scientific Inc, Madrid, Spain). The homogenate was centrifuged at $7500 \mathrm{xg}$ for $2 \mathrm{~min}$ at $4^{\circ} \mathrm{C}$, and the supernatant was used for protein analysis. 
Total mitochondrial protein content was measured by the method of Bradford [9]. For analysis, $40 \mu \mathrm{g}$ of total mitochondrial protein was solubilized and boiled for $3 \mathrm{~min}$ in Laemmli sample buffer containing $5 \%$ 2- $\beta$-mercaptoethanol. Western blot and CPT1A detection was performed as described above.

\section{Histological analysis}

rWAT and liver samples from all groups were processed. Firstly, fixed samples were dehydrated in graded series of ethanol, cleared in xylene and embedded in paraffin blocks. Then, five micrometre-thick sections of tissues were cut with a microtome and mounted on slides.

For histological analysis, slides were stained with hematoxylin and eosin, dehydrated with ethanol, cleared in xylene and mounted with Eukitt (Panreac Quimica SA). For each rWAT and liver sample, 2-3 photos from the most preserved and representative sections of the slides were digitalized from light microscopy (Zeiss Axioskop 2 microscope) connected with AxioCam Icc3 digital camera (Carl Zeiss, S.A., Barcelona, Spain). In liver sections, the presence of fatty vesicles was studied by using the software AxioVision 40V 4.6.3.0. (Carl Zeiss, Imaging Solutions GmbH, Germany). Morphometric analyses were performed in rWAT. The diameter of all adipocytes from each photo of rWAT was measured by using the software AxioVision 40V 4.6.3.0. mentioned above, and then averaged. Only adipocytes which had an intact membrane were measured. Image analyses from all samples and groups were examined in a blind fashion.

\section{Measurement of circulating parameters}

Circulating parameters were measured at the age of 6 months under fed and/or fasting conditions. Blood glucose concentration was measured by Accu-Chek Glucometer (Roche Diagnostics, Barcelona, Spain). Commercial enzyme-linked immunosorbent assay (ELISA) kits were used for the quantification of circulating plasma levels of hormones: insulin (Mercodia AB, Uppsala, Sweden), and adiponectin, leptin and TNF $\alpha$ (R\&D Systems, Minneapolis, MN, USA), according to the manufacturer's instructions. Absorbance of the samples was read with a spectrophotometer Tecan Sunrise Absorbance Reader. A fluorimetric assay was used for the quantification of $\beta$-hydroxybutyrate (BHB) plasma levels (kit from BEN S.r.l.-Biochemical enterprise). Fluorescense was detected by using a spectrofluorimeter Mithras LB 940 (Berthold Technologies GmgH \& Co KG, Bad Wildbad, Germany).

The homeostatic model assessment for insulin resistance (HOMA-IR) was used to assess insulin resistance. It is calculated from fasting insulin and glucose concentration using the formula of Matthews et al. [10]. HOMA-IR= fasting glucose $(\mathrm{mmol} / \mathrm{L}) \mathrm{x}$ fasting insulin $(\mathrm{mU} / \mathrm{L}) / 22.5$.

\section{Hepatic triglycerides, extraction and quantification}

Lipid extraction was performed in the liver of 6-month-old animals to evaluate hepatic TG content. The protocol followed was described in Caimari et al. [11] with some modifications. Briefly, 50-100mg of liver was mixed with $1 \mathrm{~mL}$ of hexane/isopropanol (3:2, vol/vol). Hepatic lipid extracts were resuspended in $1.2 \mathrm{~mL}$ of LPL buffer $\left(28.75 \mathrm{mM}\right.$ Pipes, $57.4 \mathrm{mM} \mathrm{MgCl} 2 \cdot 6 \mathrm{H}_{2} 0,0.569 \mathrm{mg} / \mathrm{mL}$ bovine serum albumin-fatty acid free) with sodium dodecyl sulfate (SDS) $0.1 \%$. Then, samples were sonicated for $30 \mathrm{~s}$, and tubes were left overnight in an orbital shaker at room temperature and protected from light. On the following day, tubes were cold sonicated with three pulses of 30s each, and their TG levels were measured immediately using a commercial enzymatic colorimetric kit (Triglyceride (INT) 20, Sigma Diagnostics, St Louis, MO, USA).

\section{Quantification of hepatic glycogen levels}

Hepatic glycogen was quantified in liver samples from 6-month-old animals. Glycogen isolation was performed by digestion of $0.3-0.8 \mathrm{~g}$ of liver in $1 \mathrm{~mL}$ of $30 \% \mathrm{KOH}$ at $100^{\circ} \mathrm{C}$ for $10 \mathrm{~min}$. Glycogen was precipitated overnight at $-20^{\circ} \mathrm{C}$ with $2 \mathrm{~mL}$ of $100 \%$ ethanol and collected by centrifugation at $3000 \mathrm{rpm}$ for $30 \mathrm{~min}$ at $4^{\circ} \mathrm{C}$. The precipitate was redissolved in $1 \mathrm{~mL}$ of $8 \%$ tricholoracetic acid (TCA) and centrifuged at $3000 \mathrm{rpm}$ for $15 \mathrm{~min}$ at $4^{\circ} \mathrm{C}$; the supernatant was stored at $4^{\circ} \mathrm{C}$, whereas the pellet was redissolved in $1 \mathrm{~mL}$ of $8 \% \mathrm{TCA}$ and centrifuged at $3000 \mathrm{rpm}$ for $15 \mathrm{~min}$ at $4^{\circ} \mathrm{C}$; the resulting supernatant was added to the stored one. Glycogen was again obtained from the supernatant by precipitation with $4 \mathrm{~mL}$ of $96 \%$ cold ethanol followed by centrifugation at $3000 \mathrm{rpm}$ for $15 \mathrm{~min}$ at $4^{\circ} \mathrm{C}$. Finally, the pellet was then redissolved in $1 \mathrm{~mL}$ of water. Glycogen concentration was measured with the anthrone reagent as previously described [12]. 
Indirect calorimetry and locomotive activity measurements

At the age of 3 months, animals were monitored for $24 \mathrm{~h}$ to assess energy expenditure by indirect calorimetry and locomotive activity by using the LabMaster-CaloSys-Calorimetry System (TSE Systems, Bad Homburg, Germany). Before starting measurements, and in order to reduce potential stress, animals were individually housed and acclimated to the respiratory cages for $24 \mathrm{~h}$. Then, data on gas exchanges $\left(\mathrm{VO}_{2} ; \mathrm{ml}\right.$ $\mathrm{kg}^{-1} \mathrm{~h}^{-1}$ and $V C \mathrm{O}_{2} ; \mathrm{ml} \mathrm{kg}^{-1} \mathrm{~h}^{-1}$ ) were measured via an open-circuit indirect calorimetry system for $24 \mathrm{~h}$. To calculate energy expenditure $(\mathrm{kcal} / \mathrm{h})$, rates of oxygen consumption and carbon dioxide production were monitored for $5 \mathrm{~min}$ every $45 \mathrm{~min}$ for each animal or reference cage (our system can handle 8 animal cages and 1 reference cage, simultaneously). Locomotive activity (counts/h) was measured continuously by an infrared beam system integrated in the LabMaster System for $24 \mathrm{~h}$.

\section{Blood pressure measurement}

Systolic blood pressure (SBP) was measured when animals were 5 months old. SBP was determined without anaesthesia using non-invasive blood pressure methodology. It consists of using a tail-cuff sphygmomanometer with a photoelectric sensor (Niprem 546, Cibertec S.A., Spain) placed on the animal's tail to occlude the blood flow. Heart rate was also registered. Niprem software V1.8 was used to determine the SBP value and heart rate value. For each rat, SBP and heart rate values were calculated as the mean of a minimum of five measurements.

\section{Gene expression analysis in liver}

Total RNA was extracted from liver by EZNA® TOTAL RNA kit I (Omega Bio-Tek Inc., Norcross, GA, USA) following the manufacturer's instructions. Isolated RNA was quantified using the NanoDrop ND-1000 spectrophotometer (NanoDrop Techonologies, Ins., Wilmington, DE) and its integrity confirmed using agarose $1 \%$ gel electrophoresis.

Real-time quantitative polymerase chain reaction (RT-qPCR) was used to measure mRNA expression levels in liver of Acaca (Acetyl-CoA carboxylase subunit alpha), Cd68 (cluster of differentiation 68), Fasn (fatty acid synthase), G6pd (glucose-6-phosphate dehydrogenase), ObRb (long form leptin receptor) and Tnfa (tumor necrosis factor alpha). Gdi1 (guanosine diphosphate (GDP) dissociation inhibitor 1) and Rn18s (18S ribosomal RNA) were used as housekeeping genes. All primers used for RT-qPCR amplification were obtained from Sigma Genosys (Sigma Aldrich Química SA, Madrid, Spain) and sequences are described in $[6,13,14]$, except for: G6pd (forward sequence: 5'-CGAACCACATCTCCTCTCTG-3' and reverse sequence 5'-ATCAAAATAGCCCCCACGAC-3') and Cd68 (forward sequence: 5'-AATGTGTCCTTCCCACAAGC-3' and reverse sequence 5'-GGCAGCAAGAGAGATTGGTC - 3 ').

Total RNA $(0.25 \mu \mathrm{g}$; in a final volume of $5 \mu \mathrm{l})$ was denatured for $10 \mathrm{~min}$ at $65^{\circ} \mathrm{C}$ and then reverse transcribed to cDNA using murine leukemia virus reverse transcriptase (Applied Biosystem, Madrid Spain) for $15 \mathrm{~min}$ at $20^{\circ} \mathrm{C}$, for $30 \mathrm{~min}$ at $42^{\circ} \mathrm{C}$, with a final step of $5 \mathrm{~min}$ at $95^{\circ} \mathrm{C}$ in an Applied Biosystems 2720 Thermal Cycler (Applied Biosystem). Each qPCR was performed from diluted (1/10) cDNA template, forward and reverse primers $(5 \mu \mathrm{M}$ and $10 \mu \mathrm{M})$, and Power SYBER Green PCR Master Mix (Applied Biosystems, Foster City, CA). qPCR was performed using the Applied Biosystems Step OnePlusTM Real-Time PCR Systems (Applied Biosystems) with the following profile: $10 \mathrm{~min}$ at $95^{\circ} \mathrm{C}$, followed by a total of 40 two-temperature cycles $\left(15 \mathrm{~s}\right.$ at $95^{\circ} \mathrm{C}$ and $1 \mathrm{~min}$ at $\left.60^{\circ} \mathrm{C}\right)$. To verify the purity of the products, a melting curve was produced after each run according to the manufacturer's instructions. The threshold cycle was calculated by the instrument's software (StepOne Software version 2.2). Relative gene expression numbers were calculated as a percentage of male control AAV-Gfp (C-C) rats, using the 2- $\Delta \Delta \mathrm{Ct}$ method [15].

\section{Statistical analysis}

Data are mean \pm standard error of the mean (S.E.M.). Multiple comparisons were assessed by two-way or repeated measures analysis of variance (ANOVA) to determine the effects of calorie restriction during gestation, and AAV-Cpt1am injection vs AAV-Gfp. Single comparisons between groups were assessed by Student's $t$ test and the effect of fasting conditions by Paired $t$ test. Threshold of significance was set at $\mathrm{p}<0.05$, unless indicated. Analysis was performed with SPSS for Windows (SPSS version 19.0, Chicago, IL). 
Fig. 1. Protein levels of CPT1A measured in whole-protein extracts of liver (a), or in the mitochondrial protein fraction (b) from 6-month-old offspring of control dams injected on postnatal day 18 with Gfp and Cpt1am vectors (C-C and C-CPT, respectively) and offspring of calorie restricted dams during gestation injected with Gfp and Cpt1am vectors (CR-C and CR-CPT, respectively). Data are mean \pm S.E.M. (n= 9-11 animals per group). Statistics: $\Omega$, Cpt1am vs Gfp-injection, $(\mathrm{p}<0.05$, Student's $t$ test). Abbreviations: carnitine palmitoyltransferase 1A (CPT1A); no significant differences (n.s.).

\section{Results}

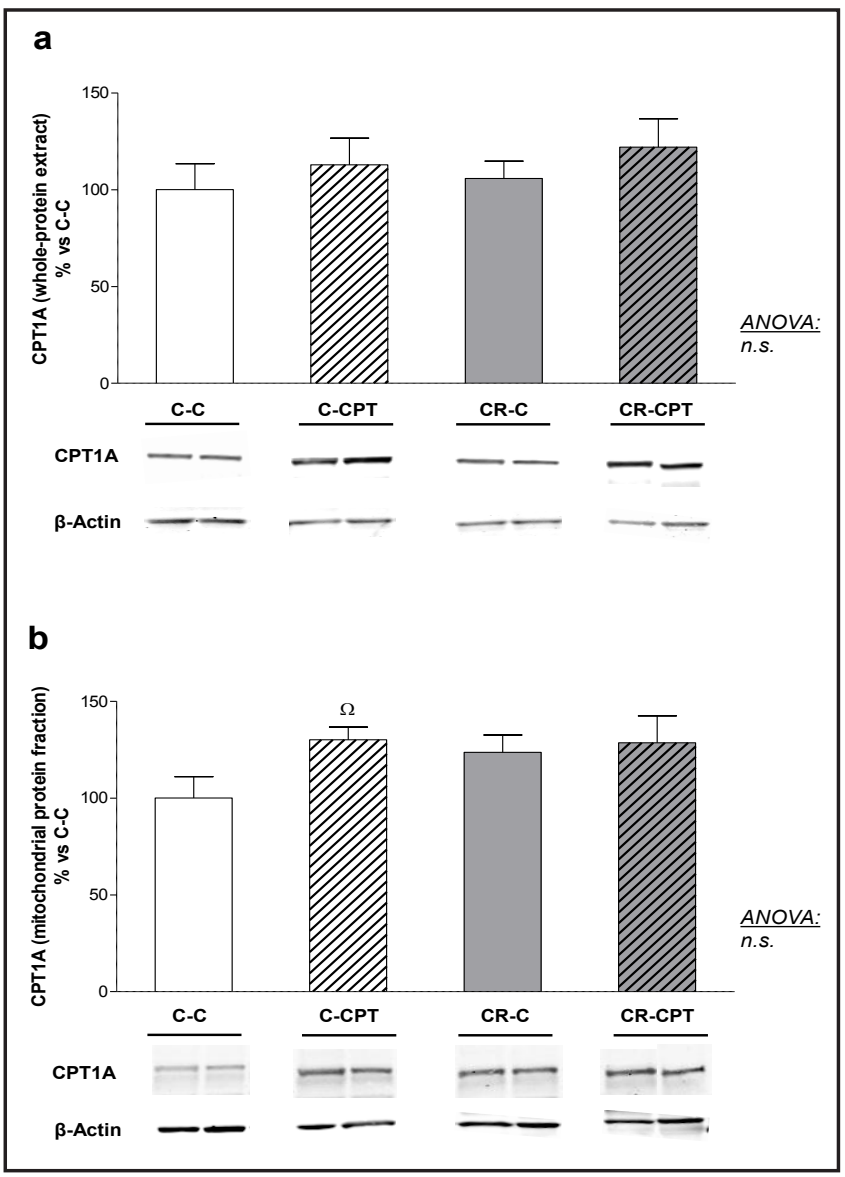

Vector insertion verification in hepatic cells

The AAV-Gfp and AAV-Cpt1am constructs used here were the same as in a previous study [7]. Their capacity to insert in hepatic cells and drive overexpression of the target genes had been previously proven [7].

Since vector insertion was made at an early age of life (postnatal day 18), relative Cpt1a expression was expected to be decreased as the animals grew. Western Blot analysis of CPT1A in liver was performed in adult animals to verify whether overexpression of $C p t 1 a$ remained at the age of 6 months. Fig. 1 shows protein levels of hepatic CPT1A in the whole protein extract in liver (Fig. 1a) and levels of hepatic CPT1A in the mitochondrial protein fraction in liver (Fig. 1b). When analysing the whole protein extract, we did not observe significant changes in CPT1A protein levels due to the injection of AAV-Cpt1am vectors (no significant differences by two-way ANOVA). C-CPT and CR-CPT animals tended toward slightly higher but not significantly different levels of CPT1A than those animals injected with controlvectors. When analysing the mitochondrial protein extract, C-CPT animals showed greater CPT1A levels than C-C rats ( $\mathrm{p}<0.05$, Student's $t$ test). No changes were observed in CPT1A protein content by effect of maternal calorie restriction during gestation (no significant differences by two-way ANOVA).

The presence of GFP in hepatocytes of animals injected with control (AAV-Gfp) vectors was used to demonstrate the achievement of injection and vector insertion. AAV-Cpt1am injected animals were used as a negative control. Relative Gfp expression was also expected to decrease as the animals grew, but was still detected in adult animals. Fig. 2 shows digital images of representative liver slides of C-C, C-CPT, CR-C and CR-CPT animals acquired by using confocal laser scanning microscopy. Fluorescent signals from GFP were found as spots distributed in the cytoplasm of hepatocytes of C-C and CR-C animals (GFP images), while 


\section{Cellular Physiology $\quad$ Cell Physiol Biochem 2014;33:1498-1515 and Biochemistry

Fig. 2. GFP detection in hepatocytes from 6-monthold offspring of control dams and calorie restricted dams during gestation, injected on postnatal day 18 with Gfp (C-C and $\mathrm{CR}-\mathrm{C}$, respectively) compared to those AAV-Cpt1am injected ones (C-CPT and CR$\mathrm{CPT}$, respectively). Detection was made by confocal laser scanning microscopy of frozen liver sections stained with DAPI for nucleus identification. Excitation wavelength was set at $405 \mathrm{~nm}$ (for DAPI) and 488nm (for GFP). Images were scanned at $64 \mathrm{X}$. Abbreviations: blue-fluorescence DAPI dilactate (DAPI) and green fluorescence protein (GFP).



Table 1. Body weight at different ages and weight of WAT depots and liver at sacrifice. At birth, data are mean \pm S.E.M ( $n=19-21$ animals per group) of the offspring of control and calorie restricted dams during gestation (control and CR, respectively). From PND-18, data are mean \pm S.E.M (n=9-11 animals per groups) of the offspring of control dams injected in postnatal day 18 with Gfp and Cpt1am vectors ( $\mathrm{C}-\mathrm{C}$ and $\mathrm{C}-\mathrm{CPT}$, respectively) and the offspring of calorie restricted dams during gestation injected with Gfp and Cpt1am vectors (CR-C and CR-CPT, respectively). Abbreviations: inguinal white adipose tissue (iWAT), postnatal day (PND), and retroperitoneal white adipose tissue (rWAT)

\begin{tabular}{|c|c|c|c|c|c|}
\hline \multirow{3}{*}{$\begin{array}{l}\text { Body weight (g) } \\
\text { Birth }\end{array}$} & \multirow{4}{*}{$\begin{array}{l}\text { Age } \\
\text { PND-1 }\end{array}$} & \multicolumn{2}{|c|}{ Control } & \multicolumn{2}{|c|}{ CR } \\
\hline & & \multirow{2}{*}{\multicolumn{2}{|c|}{$6.72 \pm 1.16$}} & \multirow{2}{*}{\multicolumn{2}{|c|}{$6.72 \pm 0.20$}} \\
\hline & & & & & \\
\hline & & C-C & C-CPT & CR-C & CR-CPT \\
\hline AAV-Injection & ND-18 & $35.5 \pm 0$. & 35.8 & $35.6 \pm 1.6$ & 1.4 \\
\hline Wea & ND & $45.8 \pm 1.2$ & 46.4 & 2.4 & \\
\hline F-diet & $4 \mathrm{mo}$ & $411 \pm 9$ & 401 & $407 \pm 9$ & 39 \\
\hline After HF-diet & 6 mon & $479 \pm 10$ & 471 & $478 \pm 14$ & 464 \\
\hline \multicolumn{6}{|l|}{ WAT weight (g) } \\
\hline iWAT & 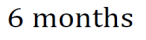 & $2.4 \pm 0.8$ & 13.2 & $13.7 \pm 1.2$ & 11. \\
\hline rWA & $6 \mathrm{mc}$ & $17.8 \pm 1.4$ & $18.4 \pm$ & $18.9 \pm 1.7$ & $18.5 \pm 1.2$ \\
\hline Liver weight (g) & 6 months & $13.6 \pm 0.4$ & $12.8 \pm 0.6$ & $12.5 \pm 0.3$ & $12.6 \pm 0.5$ \\
\hline
\end{tabular}

no green fluorescence emission was observed in hepatocytes of C-CPT and CR-CPT. Nuclear DAPI staining is also shown in blue (DAPI images). Merge images show the superposition of DAPI and GFP images, evidencing the cell localisation of green fluorescence. 
Table 2. Circulating parameters at the age of 6 months. Circulating parameters under fed and fasting conditions from 6-month-old offspring of control dams injected in postnatal day 18 with Gfp and Cpt1am vectors (C-C and C-CPT, respectively) and offspring of calorie restricted dams during gestation injected with Gfp and Cpt1am vectors (CR-C and CR-CPT, respectively). Data are mean \pm S.E.M (n=9-11 animals per group) Statistics: RxT, interaction between maternal calorie restriction during gestation and Cpt1am-injection; $R$, effect of maternal calorie restriction during gestation; T, effect of Cpt1am-injection ( $\mathrm{p}<0.05$, two-way ANOVA). \#, fasting vs feeding conditions ( $\mathrm{p}<0.05$, Paired $t$ test); *, CR vs Control animals; ${ }^{\Omega}$, Cpt1am vs Gfpinjection ( $\mathrm{p}<0.05$, Student's $t$ test). Abbreviations: BHB, ( $\beta$-hydroxybutyrate), HOMA-IR (insulin resistance HOMA index), L/A ratio (leptin-to-adiponectin ratio), TG (triglycerides) and TNF $\alpha$ (tumor necrosis factor alpha)

\begin{tabular}{|c|c|c|c|c|c|c|}
\hline & & $\mathrm{C}-\mathrm{C}$ & C-CPT & CR-C & CR-CPT & ANOVA \\
\hline \multirow{2}{*}{ Glucose (mg/dL) } & Fed & $121 \pm 3$ & $115 \pm 2$ & $111 \pm 4$ & $117 \pm 4$ & \\
\hline & Fasting & $104 \pm 3^{\#}$ & $107 \pm 4 \# \mathrm{p}=0.06$ & $110 \pm 4$ & $97.1 \pm 1.0^{\#, \Omega, *}$ & $R x T$ \\
\hline \multirow{2}{*}{ Insulin $(\mu \mathrm{g} / \mathrm{L})$} & Fed & $2.09 \pm 0.18$ & $2.84 \pm 0.54$ & $2.54 \pm 0.46$ & $3.54 \pm 0.56$ & \\
\hline & Fasting & $0.974 \pm 0.154 \#$ & $0.583 \pm 0.100^{\#, \Omega}$ & $1.62 \pm 0.41$ & $1.19 \pm 0.24 \#, *$ & $R$ \\
\hline \multirow{2}{*}{$\mathrm{BHB}(\mu \mathrm{mol} / \mathrm{L})$} & Fed & $666 \pm 84$ & $652 \pm 70$ & $466 \pm 112$ & $596 \pm 79$ & \\
\hline & Fasting & $841 \pm 73$ & $911 \pm 222$ & $2000 \pm 194 \#, *$ & $1433 \pm 205^{\#, \Omega}$ & $R$ \\
\hline \multirow{2}{*}{$\mathrm{TG}(\mathrm{mg} / \mathrm{mL})$} & Fed & $2.23 \pm 0.31$ & $1.67 \pm 0.28$ & $1.57 \pm 0.22$ & $1.54 \pm 0.22$ & \\
\hline & Fasting & $0.408 \pm 0.042^{\#}$ & $0.446 \pm 0.095^{\#}$ & $0.457 \pm 0.078^{\#}$ & $0.380 \pm 0.096^{\#}$ & \\
\hline \multirow{2}{*}{ Leptin $(\mu \mathrm{g} / \mathrm{L})$} & Fed & $12.2 \pm 1.2$ & $12.4 \pm 1.4$ & $12.4 \pm 1.4$ & $11.2 \pm 1.1$ & \\
\hline & Fasting & $4.93 \pm 0.58^{\#}$ & $5.97 \pm 0.77 \#$ & $7.25 \pm 1.0^{\#,{ }^{*} \mathrm{p}=0.062}$ & $6.76 \pm 0.67 \#$ & \\
\hline \multirow{2}{*}{ Adiponectin (mg/L) } & Fed & $9.36 \pm 0.82$ & $10.4 \pm 0.9$ & $8.89 \pm 0.37$ & $9.05 \pm 1.20$ & \\
\hline & Fasting & $8.76 \pm 0.62$ & $8.85 \pm 0.55$ & $8.05 \pm 0.59$ & $9.02 \pm 0.50$ & \\
\hline \multirow{2}{*}{$\mathrm{L} / \mathrm{A}$ ratio $(\mu \mathrm{g} / \mathrm{mg})$} & Fed & $1.31 \pm 0.14$ & $1.31 \pm 0.20$ & $1.41 \pm 0.15$ & $1.42 \pm 0.21$ & \\
\hline & Fasting & $0.58 \pm 0.08^{\#}$ & $0.68 \pm 0.08^{\#}$ & $0.92 \pm 0.15^{\#, *}$ & $0.70 \pm 0.07 \#$ & \\
\hline HOMA-IR & Fasting & $6.25 \pm 1.06$ & $3.77 \pm 0.67 \Omega \mathrm{p}=0.07$ & $10.7 \pm 2.8$ & $6.97 \pm 1.14^{*}$ & $R, T$ \\
\hline $\mathrm{TNF} \alpha(\mathrm{pg} / \mathrm{mL})$ & Fed & $4.40 \pm 0.80$ & $4.66 \pm 0.80$ & $6.62 \pm 0.77^{*} \mathrm{p}=0.066$ & $5.50 \pm 1.15$ & \\
\hline
\end{tabular}

Fig. 3. Protein levels of total AKT and $\mathrm{pAKT} /$ total AKT ratio in liver from 6-month-old offspring of control dams injected on postnatal day 18 with Gfp and Cpt1am vectors (C-C and C-CPT, respectively) and offspring of calorie restricted dams during gestation injected with $G f p$ and Cpt1am vectors (CR-C and CR$\mathrm{CPT}$, respectively). Data are mean \pm S.E.M. ( $n=9-11$ animals per group). $\beta$-Actin was used a housekeeping protein. Statistics: $R x T$, interaction between maternal calorie restriction during gestation and Cpt1aminjection, (two-way ANOVA). $\Omega$, Cpt1am vs Gfp-injection); *, CR vs Control animals $(\mathrm{p}<0.05$, Student's $t$ test). Abbreviations: total protein kinase B (total AKT) and phosphorylated AKT on Serine 473 (pAKT).



AAV-Cpt1am treatment at early ages improved insulin sensitivity and prevented increased adiposity size occurring in the offspring of calorie restricted dams during gestation without affecting body weight

Body weight. As shown in Table 1, moderate maternal calorie restriction during the first 12 days of pregnancy did not result in different offspring body weight at birth with respect to their controls. Neither were significant differences found between control and CR animals 
Fig. 4. Triglyceride content in liver (a); representative liver slides stained with hematoxylin/eosin (x20); (b) and hepatic glycogen content (c) from 6-month-old offspring of control dams injected on postnatal day 18 with Gfp and Cpt1am vectors (C-C and C-CPT, respectively) and offspring of calorie restricted dams during gestation injected with Gfp and Cpt1am vectors (CR-C and CR-CPT, respectively). Data are mean \pm S.E.M. $(\mathrm{n}=9-11$ animals per group). Statistics: $R$, effects of maternal calorie restriction during gestation ( $p=0.087$, two-way ANOVA); $T$, effects of Cpt1am-injection ( $\mathrm{p}=0.087$, two-way ANOVA). *, CR vs Control animals, $(\mathrm{p}<0.05$, Student's $t$ test $)$. Abbreviations: triglycerides (TG). Symbol images: $\mathrm{V}$, indicate a central vein; the arrows indicate some lipid droplets.



throughout the study period, either under NF-diet or when moved to a HF diet. Neither did AAV-Cpt1am injection affect body weight of animals compared to their AAV-Gfp injected control ones.

The weight of WAT depots (inguinal or retroperitoneal) was not different between groups at the age of 6 months.

Circulating parameters. Table 2 shows circulating levels of glucose, insulin, BHB, TG, leptin, adiponectin and TNF $\alpha$ of control (C-C and C-CPT) and CR (CR-C and CR-CPT) animals at the age of 6 months under feeding or $12 \mathrm{~h}$ fasting conditions, as indicated. Leptin to adiponectin (L/A) ratio and HOMA-IR are also presented. CR animals (both CR-C and CRCPT) showed higher fasted insulin and HOMA-IR than controls $(\mathrm{p}<0.05$, two-way ANOVA). It is worth noting that, AAV-Cpt1am injected animals showed lower fasted insulin levels (only control animals, $\mathrm{p}<0.05$, Student's $t$ test) and lower HOMA-IR (both control and CR animals, $\mathrm{p}<0.05$, two-way ANOVA) than their respective AAV-Gfp controls. CR-CPT animals also showed lower fasted glucose levels than CR-C animals ( $\mathrm{p}<0.05$, Student's $t$ test). CR-CPT animals also showed a response to fasting conditions, regarding glucose and insulin levels, while this response was not shown in CR-C animals.

Concerning leptin, CR-C animals revealed a trend to higher leptin levels under fasting conditions than controls ( $\mathrm{p}=0.062$, Student's $t$ test). In addition, although adiponectin levels were not significantly different between groups, L/A ratio of fasted CR-C animals was significantly higher compared to C-C animals ( $\mathrm{p}<0.05$, Student's $t$ test). Differences were not observed between CR-CPT and C-CPT animals. 
Fig. 5. Adipocyte size in rWAT (a) and images (20x) of rWAT sections with hematoxylin/eosing staining (b) from 6-monthold offspring of control dams injected on postnatal day 18 with Gfp and Cpt1am vectors (C-C and C-CPT, respectively) and offspring of calorie restricted dams during gestation injected with Gfp and Cpt1am vectors (CR-C and CR-CPT, respectively). Data are mean \pm S.E.M. $(n=9-11$ animals per group). Statistics: $R x T$, interaction between maternal calorie restriction during gestation and Cpt1am-injection ( $\mathrm{p}<0.05$, two-way ANOVA). *, CR vs Control animals; $\Omega$, Cpt1am vs Gfp-injection $(\mathrm{p}<0.05$, Student's $t$ test). Abbreviations: rWAT (retroperitoneal white adipose tissue).

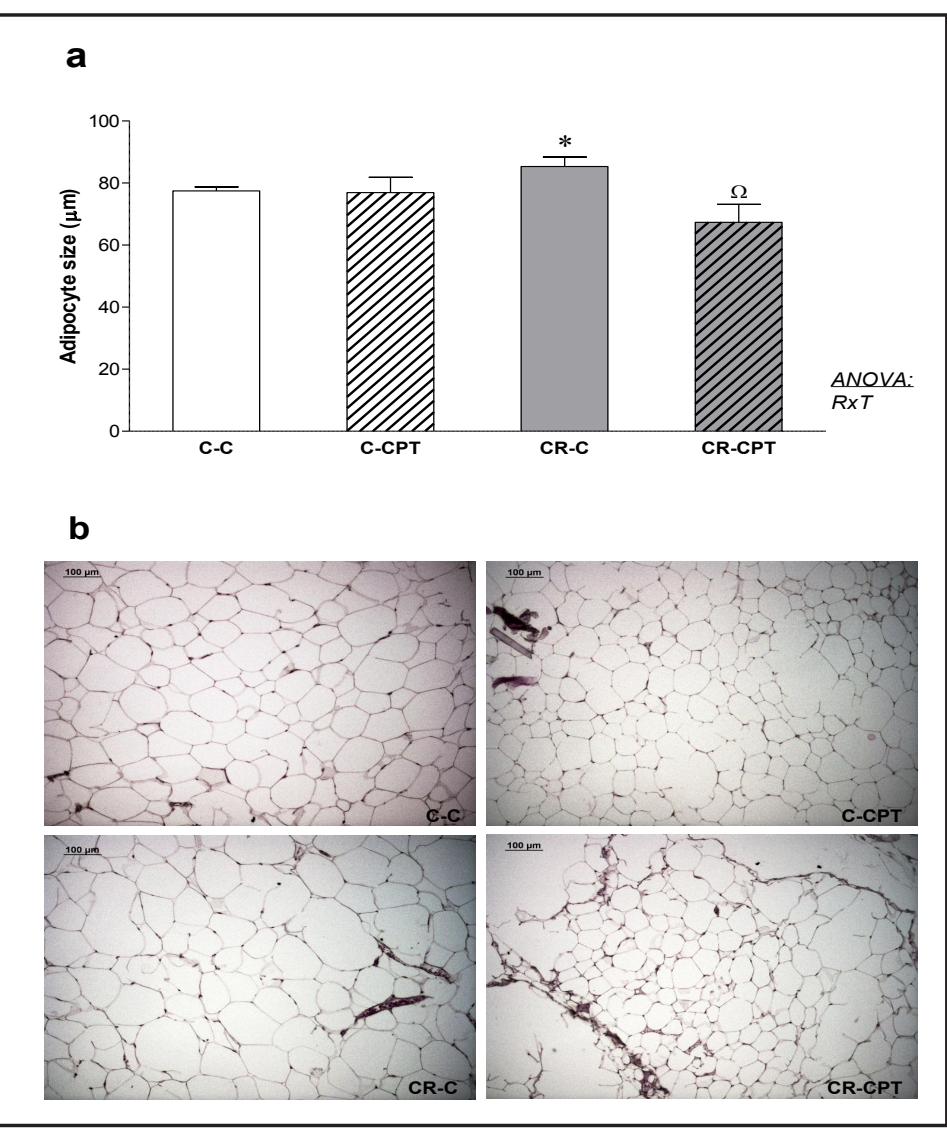

Regarding BHB, under fasting conditions, CR animals showed higher levels than their controls ( $\mathrm{p}<0.05$, two-way ANOVA); CR-CPT animals displayed lower levels than CR-C animals $(\mathrm{p}<0.05$, Student's $t$ test). No differences between groups were observed concerning TG levels. Finally, plasma levels of TNF $\alpha$ tended toward being higher in CR-C animals compared to $\mathrm{C}-\mathrm{C}$ rats ( $\mathrm{p}=0.066$, Student's $t$ test). No changes were observed between the other groups of animals.

Protein levels of total AKT and pAKT in liver. The potential effect of increased hepatic Cpt1a expression at early ages on insulin signalling was evaluated by studying total AKT and pAKT in liver at the age of 6 months (Fig. 3). CR animals injected with AAV-Cpt1am vectors showed a lower pAKT/total AKT ratio compared to CR-C and C-C animals $(\mathrm{p}<0.05$, Student's $\mathrm{t}$ test). Thus, an interaction between calorie restriction and Cpt1am-injection was observed for total AKT and pAKT/total AKT ratio ( $\mathrm{p}=0.057$ and 0.056 , respectively, two-way ANOVA).

Composition and histological analyses of liver and rWAT. Fig. 4a shows the hepatic content of TG of animals at the age of 6 months. CR-C animals tended toward displaying higher hepatic TG levels than their controls ( $\mathrm{p}=0.081$, Student's $t$ test) while no differences were observed between the other groups. Fig. $4 \mathrm{~b}$ shows representative images of hematoxylin/ eosin stained liver slides of animals from the different groups. All the animals presented fatty vesicles in their hepatocytes but CR animals showed a greater amount of fat vesicles than control animals, especially CR-C animals. Interestingly, fewer fatty vesicles were observed in CR-CPT animals compared to those injected with control-vectors.

Regarding hepatic glycogen content (Fig. 4c), AAV-Cpt1am injected animals revealed a trend to higher levels, although differences did not reach statistical significance $(p=0.087$, two-way ANOVA).

Fig. 5a shows the diameter of adipocytes measured in sections of rWAT from animals at the age of 6 months. Representative rWAT sections stained with hematoxylin/eosin of the different groups of animals are also given (Fig. 5b). Although no significant differences were observed concerning the weight of WAT depots, adipocytes of CR-C animals had a larger 
Fig. 6. Energy expenditure (a), locomotive activity (b) and systolic blood pressure (c) of offspring of control dams injected on postnatal day 18 with Gfp and Cpt1am vectors (C-C and C$\mathrm{CPT}$, respectively) and offspring of calorie restricted dams during gestation injected with Gfp and Cpt1am vectors (CR-C and CR-CPT, respectively), at the age of 3 months (for $a$ and $b$ ) and at the age of 5 months (for c). Data are mean \pm S.E.M. (n= 9-11 animals per group). Statistics: $L x R x T$, interaction between light, maternal calorie restriction during gestation and Cpt1am-injection; $L x R$, interaction between light and maternal calorie restriction during gestation; $L$, effect of light; $R$, effect of maternal calorie restriction during gestation, $(\mathrm{p}<0.05$, repeated measures ANOVA). $\lambda$, nocturnal $v s$ diurnal phase $(\mathrm{p}<0.05$, Paired $t$ test). *, CR vs Control animals; $\Omega$, Cpt1am vs Gfp-injection, $(\mathrm{p}<0.05$, Student's $t$ test). Abbreviations: systolic blood pressure (SBP).



diameter than C-C animals; interestingly, this effect was not seen in AAV-Cpt1am injected CR animals. CR-CPT animals presented adipocytes with a significantly lower diameter than CR-C rats $(\mathrm{p}<0.05$ two-way ANOVA).

AAV-Cpt1am treatment at early ages restored changes in energy metabolism, locomotive activity and systolic blood pressure programmed by calorie restriction during gestation

Energy expenditure. Energy expenditure was measured by indirect calorimetry at the age of 3 months. As shown in Fig. 6a, CR animals, both CR-C and CR-CPT, showed lower energy expenditure than their controls $(\mathrm{p}<0.05$, repeated measures ANOVA) and especially during the nocturnal period ( $\mathrm{p}<0.05$, Student's $t$ test). Despite the lower energy expenditure observed in CR animals, CR-CPT rats displayed higher energy expenditure during the nocturnal period than CR-C animals ( $\mathrm{p}<0.05$, Student's $t$ test). Energy expenditure was significantly higher during the nocturnal period in all groups of animals than during the diurnal period $(\mathrm{p}<0.05$, repeated measures ANOVA).

Locomotive activity. Locomotive activity of animals at the age of 3 months is shown in Fig. 6b. CR-C animals showed a trend to lower locomotive activity compared to their controls; this tendency was not shown in CR-CPT animals, which exhibited similar levels to control animals. In fact, CR-CPT animals displayed higher activity than CR-C animals during the diurnal period $(\mathrm{p}<0.05$, Student's $t$ test), but a trend toward higher activity was also observed during the nocturnal phase ( $\mathrm{p}=0.073$, Student's $t$ test). Interactive effects were found between light (diurnal or nocturnal period), calorie restriction during gestation and Cpt1am-injection ( $\mathrm{p}<0.05$, repeated measures ANOVA). When diurnal and nocturnal period were analysed separately, an interaction between calorie restriction and Cpt1am-injection 
Fig. 7. mRNA levels of selected genes in liver from 6-month-old offspring of control dams injected on postnatal day 18 with Gfp and Cpt1am vectors (C-C and C-CPT, respectively) and offspring of calorie restricted dams during gestation injected with Gfp and Cpt1am vectors (CR-C and CR-CPT, respectively). Data are mean \pm S.E.M. $(n=9-11$ animals per group). Statistics: $R x T$, interaction between maternal calorie restriction during gestation and Cpt1am-injection; $T$, effects of Cpt1am-injection; $R$, effects of maternal calorie restriction during gestation ( $\mathrm{p}<0.05$, two-way ANOVA). *, CR vs Controls; $\Omega$, Cpt1am vs Gfp-injection


animals, ( $<<0.05$, Student's $t$ test). Abbreviations: Acetyl-CoA carboxylase subunit alpha (Acaca), cluster of differentiation 68 (Cd68), fatty acid synthase (Fasn), glucose-6-phosphate dehydrogenase (G6pd), long form leptin receptor $(\mathrm{ObRb})$ and tumor necrosis factor alpha $(\mathrm{Tn} f a)$.

was found during the nocturnal period ( $\mathrm{p}<0.05$, two-way ANOVA). Considering all animals as a whole, locomotive activity during the nocturnal phase showed a positive correlation with energy expenditure ( $\mathrm{r}=0.414 ; \mathrm{p}=0.010$, Pearson's correlation).

Systolic blood pressure. SBP was measured when animals were 5 months old (Fig. 6c). CR-C animals displayed a significantly higher SBP than their C-C animals $(\mathrm{p}<0.05$, Student's $t$ test). Interestingly, CR-CPT animals did not show significant differences in SBP in comparison to C-CPT animals. Heart rate was also measured but, no differences between groups were observed (data not shown).

Effects of calorie restriction during gestation and AAV-Cpt1am treatment at an early age on the hepatic expression of leptin receptor and genes related to lipogenesis and inflammation

Fig. 7 shows mRNA expression levels of selected genes in liver of 6-month-old animals. Calorie restriction during gestation resulted in lower hepatic mRNA expression levels of leptin receptor. This effect was partially reverted by AAV-Cpt1am treatment at early stages of life. Therefore, $O b R b$ expression levels in CR-CPT animals were not different compared to their controls (C-CPT animals). Concerning the expression of lipogenesis related genes, AAVCpt1am treatment resulted in lower expression levels of G6pd ( $\mathrm{p}<0.05$, two-way ANOVA), particularly in CR animals ( $\mathrm{p}<0.05$, Student's $t$ test), and of Acaca, but only in CR animals ( $\mathrm{p}<0.05$, Student's $t$ test, and interactive effect between calorie restriction during gestation and AAV-Cpt1am injection, $\mathrm{p}<0.05$, two-way ANOVA). No significant differences were found concerning Fasn expression. AAV-Cpt1am injection resulted in lower expression levels of the inflammation-related genes, Tnfa and $C d 68$ ( $\mathrm{p}<0.05$, two-way ANOVA). In the case of Tnfa, the effect was more marked and significant by Student's $t$ test in CR animals $(\mathrm{p}<0.05)$. No significant differences between groups were found concerning mRNA expression levels of Il6 (interleukin 6) and Il1 b (interleukin 1 beta) (data not shown).

\section{Discussion}

We have previously described that $20 \%$ calorie restriction in rats during the first half of gestation results in metabolic disturbances in the offspring related to the metabolic syndrome $[5,6]$. These animals, particularly males, show in adulthood altered circulating parameters, 
impaired insulin and leptin sensitivity and a distorted profile of gene expression in key tissues involved in energy homeostasis [5, 6]. Besides, it is accepted that pharmacological or genetic strategies enabling FAO to be enhanced may be beneficial for the treatment of the metabolic disorders related to obesity [7, 8]. Orellana-Gavaldà et al. [7] described that AAVmediated expression of Cpt1am, a permanently active mutant form of CPT1A insensitive to malonyl-CoA, protected mice against HF diet-induced obesity, hepatic steatosis and insulin resistance. Interestingly, the use of AAV for gene therapy in humans has become attractive because AAV vectors show wide tissue tropism, efficient transduction, and lack of human pathology [16]. Due to the above characteristics and the need for strategies to prevent or treat obesity and its related metabolic disorders, here we aimed to assess whether an AAVmediated increased expression of Cpt1am, and hence enhanced hepatic FAO, at early ages of life is able to revert adverse metabolic malprogramming due to maternal moderate calorie restriction during gestation.

The effectiveness of the AAV-Cpt1am vector used here to mediate long-term expression of Cpt1a in liver has been previously described [7]. In our case, injection of AAV was made at early stages of life, postnatal day 18; hence the relative contribution of exogenous Cpt1a expression to the total expression was expected to decrease with the animals' growth, particularly with the increase in liver size. In fact, at the age of 6 months, AAV-Cpt1am injected animals only showed a small trend to display higher protein levels of CPT1A than animals injected with control-vectors. Higher CPT1A protein levels were only detected in $\mathrm{C}$-CPT animals compared to $\mathrm{C}-\mathrm{C}$ animals in the isolated mitochondrial protein fraction. This is attributable to the fact that AAV can infect both dividing and quiescent cells but persists in an extrachromosomal state without integrating into the genome of the host cell. Therefore, due to the lack of the elements in AAV required for their replication and encapsidation, the number of hepatocytes carrying the Cpt1am-vector is expected to become relatively lower compared to the total amount of hepatocytes as animals grew. The presence of green fluorescence in some hepatocytes of adult animals that were injected with AAV-Gfp, used as a control, proved the correct insertion of vectors in hepatic cells.

Concerning the lasting effects of maternal undernutrition during gestation, we show here that adult male offspring fed on a HF diet displayed higher fasting levels of insulin, a trend toward higher leptin levels, as well as greater HOMA-IR and L/A ratio compared to controls. In addition to HOMA-IR, L/A ratio has been proposed as a useful, reliable measure of insulin resistance and vascular risk $[17,18]$. These results suggest that the offspring of undernourished dams during the first part of gestation presents features of impaired insulin and leptin sensitivity in adulthood, in accordance with our previous results using the same animal model $[5,6]$. Notably, AAV-mediated Cpt1am expression reverted the alterations in plasma insulin levels, HOMA-IR and L/A ratio found in CR animals. Fasting insulin levels and HOMA-IR were also decreased in control animals injected with AAV-Cpt1am. Moreover, CRCPT animals also recovered the capacity to respond to feeding/fasting conditions as far as glucose and insulin levels were concerned, which was impaired in CR animals.

For further study, the potential effects of Cpt1am-injection on insulin signalling, hepatic levels of total AKT and its phosphorylated form were determined. It is known that interaction of insulin with its receptor leads to phosphorylation of insulin receptor substrate and initiates a signalling cascade that culminates in the phosphorylation of the serine/threonine-specific protein kinases AKT [19]. Once activated, AKT kinases use distinct downstream pathways to modulate metabolism, resulting in enhanced protein synthesis and cell growth, glucose uptake, glycogen synthesis, and lipogenesis [19]. Insulin resistance is associated with defective AKT activation [20]. However basal levels of pAKT have been found to be increased in HF diet fed mice, and have been related with insulin resistance [21]. Here, samples were not obtained under basal conditions, but under feeding conditions at the beginning of the light phase. However, at this time, plasma insulin levels are decreased compared to levels found during the dark phase, when animals consume most of their daily food intake [22]. Thus, although CR-C animals showed no changes in hepatic protein levels of total AKT or of the pAKT/total AKT ratio compared to their controls, CR-CPT rats 
showed a trend toward increased total protein levels of AKT compared to CR-C animals, and they displayed a decreased pAKT/total AKT ratio. Hence, the blockade of the continuously elevated AKT-dependent insulin signalling that CR-CPT animals revealed compared to CR-C could be tentatively related with an improvement in insulin sensitivity of animals, according to [21]; however additional analysis would need to be performed to verify the functioning of this signalling pathway in these animals.

Repeated exposure of the liver to elevated insulin levels has been described to induce increased hepatic TG production [23]. In agreement with this, CR-C animals, which displayed higher fasted insulin levels compared to their controls, also presented a trend to greater amount of lipid vesicles and higher TG content in liver. Notably, CR-CPT animals, which showed lower fasting insulin levels than CR-C animals, did not show the mentioned trend, and TG content was similar to that of control animals. Moreover, CR-CPT animals also showed fewer lipid vesicles than CR-C animals. The occurrence of higher fasting levels of ketone bodies in CR compared to their controls may also be related to increased TG accumulation in these animals. In fact, increased levels of plasma ketone bodies have been reported in patients with NAFLD [24]. Notably, CR-CPT animals shower lower ketone bodies than CR-C animals. Changes in liver TG content between control and AAV-Cpt1am animals may be related to lower expression levels of lipogenesis-related genes, such as G6pd and Acaca. G6PD catalyses the first, rate-limiting, step of the pentose phosphate pathway. NADPH is the important product of the reaction and is used for the reductive biosynthesis of fatty acids and cholesterol [25]. NADPH also plays an important function in the protection of the cell against oxidative agents by transferring its reductive power to glutathione disulphide via glutathione disulphide reductase [25]. Regarding the lipogenic activity of this enzyme, hepatic G6PD has been demonstrated to be regulated by nutritional and hormonal factors, particularly insulin, in function of the demand for NADPH needed for cholesterol and/fatty acid metabolism [26]. G6pd expression and activity are upregulated in rat and mouse models of obesity, hyperglycemia and hyperinsulinemia, and a role for G6pd in the development of insulin resistance in type 2 diabetes has been proposed [26]. AAV-Cpt1am injected animals, particularly CR animals, showed lower expression levels of G6pd compared to their respective controls. This could be related to lower hepatic lipogenesis activity and the relative protection of these animals to developing insulin resistance. Consistent with these results, CR-CPT animals also revealed lower mRNA expression levels of Acaca compared to their controls. This enzyme is highly expressed in liver and catalyses malonyl-CoA formation, the first step for fatty acid synthesis [27]. Moreover, malonyl-CoA also suppresses fatty acid oxidation by inhibiting CPT1A; therefore reduction of Acaca expression may also increase fat oxidation [27].

Differences between groups concerning hepatic glycogen content may also be reflecting differences in insulin sensitivity between groups. Glycogen storage and release of glucose are major functions of the liver, and insulin also plays a main role in the regulation of these processes. Although we did not directly measure glycogen synthesis, the trend to higher hepatic glycogen content in AAV-Cpt1am injected animals compared to those injected with the control-vector may suggest increased glycogen synthesis capacity. This could be tentatively related to improved insulin sensitivity in AAV-Cpt1am injected animals. Defective hepatic glycogen synthesis would be expected to exacerbate postprandial hyperglycemia, and hence have clinical implications. In this regard, human studies have shown that poorly controlled insulin dependent diabetes mellitus subjects had impaired glycogen synthesis and augmented hepatic gluconeogenesis compared to control subjects [28].

In addition to insulin, impairment in leptin sensitivity, both central and peripheral, may play a role in the metabolic disturbances associated to undernutrition during gestation [5, 6]. Here, even despite the absence of differences concerning body weight between the groups of animals, fasted CR-C animals showed a trend toward higher leptin levels than controls, suggesting some impairment in leptin sensitivity. In accordance with this, CR-C animals also displayed lower $O b R b$ mRNA levels in liver compared to their controls. Notably, AAV-Cpt1am injection at an early age was able to revert, at least partially, the negative lasting effects of 
maternal calorie restriction on leptin sensitivity, as evidenced by circulating leptin levels and hepatic $O b R b$ mRNA levels.

Later undesirable effects associated to severe maternal undernutrition during gestation (both calorie restriction and protein restriction) have also been related to impaired renal function and hypertension $[29,30]$. Hyperinsulinemia may contribute to this alteration but it seems to be particularly caused by alterations in the development of kidneys, leading to a decrease in the number of glomeruli [30]. In accordance with this, we show here that moderate maternal calorie restriction during gestation also leads to increased blood pressure in adult animals. Interestingly this increase was not seen in AAV-Cpt1am injected CR animals, which showed similar values to those of controls.

The results obtained here regarding the effects of moderate maternal calorie restriction during gestation are generally in agreement with our previous studies using the same conditions [5, 6], as well as with results from other authors using a greater degree of maternal calorie restriction (30\%) throughout gestation [29]. However, unlike our previous studies, here we did not observe significant effects of this prenatal moderate restriction on later food intake (data not shown) as animals were able to maintain similar body weight to that of controls, at least during the period studied. Neither did we observe significant differences between control and CR animals concerning fat accumulation. Nevertheless, CR-C animals showed a significant increase in the size of adipocytes in rWAT. It is widely known that adipose tissue can respond rapidly and dynamically to alterations in nutrient supply through changes in the number and size of adipocytes, thereby fulfilling its major role in whole body energy homeostasis. It is recognized that adipocyte hypertrophy (an increase in adipocyte volume) prevails in obesity [31], and exposure to a HF diet for a few days has been shown to result in a significant increase in adipocyte size [31]. Adipocyte hypertrophy has been previously described in rWAT of adult CR animals, while hyperplasia is characteristic of the subcutaneous inguinal depot and associated to the lower sympathetic innervation occurring in these animals [32]. Here, the increased size of adipocytes in CR animals compared to controls may indicate that these animals have impaired capacity to burn excess energy under HF diet conditions. Interestingly, CR-CPT animals showed a significant reduction in adipocyte size to levels similar, or even slightly lower, than controls.

Energy expenditure and locomotive activity measures are also in favour of an imbalance of energy homeostasis toward lower energy expenditure in the offspring of calorie restricted dams during gestation. These animals revealed lower energy expenditure during the nocturnal period, which can be associated to a trend to lower locomotive activity. AAVCpt1am injection in CR animals reverted the decreased locomotive activity, and this resulted in a partial recovery of energy expenditure levels.

Therefore, increased FAO at early stages of life prevents or ameliorates increased propensity of animals to develop features of the metabolic syndrome associated to maternal undernutrition during gestation. However, increased FAO may be associated with enhanced reactive oxygen species (ROS) production and a consequent inflammatory state [7]. Thus, to rule out this possibility, inflammation markers were determined.

$\mathrm{TNF} \alpha$ is a cytokine involved in systemic inflammation and appears to participate in the induction and maintenance of the subacute inflammatory state associated with obesity. TNF $\alpha$ is overproduced in fatty liver and participates in the development of insulin resistance [33]. Here we show that CR-C animals tended toward displaying higher plasma levels of $\mathrm{TNF} \alpha$ than their respective controls. These relatively high levels of TNF $\alpha$ could be due to the greater hepatic TG content of these animals and could explain, in part, their insulin resistance. AAV-Cpt1am injection in CR rats led to maintaining TNF $\alpha$ in adulthood at levels similar to their control group. Expression of Tnfa in liver was also decreased in AAV-Cpt1am injected animals in comparison to animals injected with the AAV-Gfp, the decrease being more marked in CR animals. mRNA expression levels of tissue macrophage marker Cd68 [34] were also decreased in AAV-Cpt1am injected animals, both control and CR animals. We did not observe changes in mRNA expression levels of the cytokines $I l 6$ and $I l 1 b$ in liver (data not shown), which have been described to be overproduced in fatty liver [33]. This could be due 
to the fact that here all groups of animals were under HF diet, which could be masking the potential effects of maternal undernutrition on the expression of these genes.

In summary, AAV-Cpt1am mediated increased hepatic FAO at a juvenile age is able to revert or prevent some of the metabolic alterations associated to gestational maternal calorie restriction seen in adult animals when exposed to obesogenic conditions, including impaired insulin and leptin sensitivity, and increased systolic blood pressure. This treatment is also able to improve inflammatory markers and prevent the decreased energy expenditure characteristic of these animals. Therefore, enhancement of hepatic FAO at early ages could be considered as a strategy for reverting metabolic disturbances related to developmental malprogramming.

\section{Acknowledgements}

We thank Enzo Ceresi for his help in morphological techniques. We gratefully acknowledge the Spanish Government (grant AGL2012-33692 to A.P., grant SAF2010-20039 to L.H. and grant SAF2011-30520-C02-01 to D.S.), the European Union (BIOCLAIMS FP7244995 to A.P.), the Instituto de Salud Carlos III, Centro de Investigación Biomédica en Red Fisiopatología de la Obesidad y Nutrición (CIBEROBN), EFSD/Lilly and EFSD/Janssen (research fellowships to LH) and by L'Oréal-UNESCO (research fellowship to LH). The Laboratory of Molecular Biology, Nutrition and Biotechnology (Nutrigenomics) is a member of the European Research Network of Excellence NuGO (The European Nutrigenomics Organization, EU Contract: $n^{\circ}$ FP6-506360).

\section{References}

1 Malik VS, Willett WC, Hu FB: Global obesity: Trends, risk factors and policy implications. Nat Rev Endocrinol 2013;9:13-27.

2 Taylor P, Poston L: Developmental programming of obesity in mammals. Exp Physiol 2007;92:287-298.

3 Cottrell EC, Ozanne SE: Early life programming of obesity and metabolic disease. Physiol Behav 2008;94:17-28.

4 McMillen I, MacLaughlin S, Muhlhausler B, Gentili S, Duffield J, Morrison J: Developmental origins of adult health and disease: The role of periconceptional and foetal nutrition. Basic Clin Pharmacol Toxicol 2008;102:82-89.

5 Palou M, Priego T, Sánchez J, Palou A, Picó C: Sexual dimorphism in the lasting effects of moderate caloric restriction during gestation on energy homeostasis in rats is related with fetal programming of insulin and leptin resistance. Nutr Metab (Lond) 2010;7:69.

6 Palou M, Konieczna J, Torrens JM, Sanchez J, Priego T, Fernandes ML, Palou A, Pico C: Impaired insulin and leptin sensitivity in the offspring of moderate caloric-restricted dams during gestation is early programmed. J Nutr Biochem 2012;23:1627-1639.

7 Orellana-Gavaldà JM, Herrero L, Malandrino MI, Pañeda A, Sol Rodríguez-Peña M, Petry H, Asins G, Van Deventer S, Hegardt FG, Serra D: Molecular therapy for obesity and diabetes based on a long-term increase in hepatic fatty-acid oxidation. Hepatology 2011;53:821-832.

8 Stefanovic-Racic M, Perdomo G, Mantell BS, Sipula IJ, Brown NF, O'Doherty RM: A moderate increase in carnitine palmitoyltransferase $1 \mathrm{a}$ activity is sufficient to substantially reduce hepatic triglyceride levels. Am J Physiol Endocrinol Metab 2008;294:E969-977.

-9 Bradford MM: A rapid and sensitive method for the quantitation of microgram quantities of protein utilizing the principle of protein-dye binding. Anal Biochem 1976;72:248-254.

10 Matthews DR, Hosker JP, Rudenski AS, Naylor BA, Treacher DF, Turner RC: Homeostasis model assessment: Insulin resistance and beta-cell function from fasting plasma glucose and insulin concentrations in man. Diabetologia 1985;28:412-419.

11 Caimari A, Oliver P, Palou A: Adipose triglyceride lipase expression and fasting regulation are differently affected by cold exposure in adipose tissues of lean and obese zucker rats. J Nutr Biochem 2012;23:10411050. 
12 Roe JH, Dailey RE: Determination of glycogen with the anthrone reagent. Anal Biochem 1966;15:245-250.

13 Palou M, Priego T, Sánchez J, Rodríguez AM, Palou A, Picó C: Gene expression patterns in visceral and subcutaneous adipose depots in rats are linked to their morphologic features. Cell Physiol Biochem 2009;24:547-556.

14 Ribot J, Rodriguez AM, Rodriguez E, Palou A: Adiponectin and resistin response in the onset of obesity in male and female rats. Obesity (Silver Spring) 2008;16:723-730.

15 Livak KJ, Schmittgen TD: Analysis of relative gene expression data using real-time quantitative pcr and the 2(-delta delta c(t)) method. Methods 2001;25:402-408.

16 Jazwa A. J, A., Dulak, J: New vectors and strategies for cardiovascular gene therapy. Curr Gene Ther 2007;7:7-23.

17 Finucane FM, Luan J, Wareham NJ, Sharp SJ, O'Rahilly S, Balkau B, Flyvbjerg A, Walker M, Hojlund K, Nolan JJ, Savage DB: Correlation of the leptin:Adiponectin ratio with measures of insulin resistance in nondiabetic individuals. Diabetologia 2009;52:2345-2349.

18 Satoh N, Naruse M, Usui T, Tagami T, Suganami T, Yamada K, Kuzuya H, Shimatsu A, Ogawa Y: Leptinto-adiponectin ratio as a potential atherogenic index in obese type 2 diabetic patients. Diabetes Care 2004;27:2488-2490.

19 Choi K, Kim YB: Molecular mechanism of insulin resistance in obesity and type 2 diabetes. Korean J Intern Med 2010;25:119-129.

-20 Farese RV, Sajan MP, Standaert ML: Insulin-sensitive protein kinases (atypical protein kinase c and protein kinase b/akt): Actions and defects in obesity and type ii diabetes. Exp Biol Med (Maywood) 2005;230:593605.

21 Liu HY, Hong T, Wen GB, Han J, Zuo D, Liu Z, Cao W: Increased basal level of akt-dependent insulin signaling may be responsible for the development of insulin resistance. Am J Physiol Endocrinol Metab 2009;297:E898-906.

-22 Sánchez J, Oliver P, Picó C, Palou A: Diurnal rhythms of leptin and ghrelin in the systemic circulation and in the gastric mucosa are related to food intake in rats. Pflugers Arch 2004;448:500-506.

-23 Zammit VA: Insulin stimulation of hepatic triacylglycerol secretion in the insulin-replete state: Implications for the etiology of peripheral insulin resistance. Ann N Y Acad Sci 2002;967:52-65.

24 Sanyal AJ, Campbell-Sargent C, Mirshahi F, Rizzo WB, Contos MJ, Sterling RK, Luketic VA, Shiffman ML, Clore JN: Nonalcoholic steatohepatitis: Association of insulin resistance and mitochondrial abnormalities. Gastroenterology 2001;120:1183-1192.

25 Singh SA, Asha; Srivastava, Pramod K: Regulation and properties of glucose-6-phosphate dehydrogenase: A review. Plant Physiol Biochem 2012;4:1-19.

26 Gupte SA: Targeting the pentose phosphate pathway in syndrome x-related cardiovascular complications. Drug Dev Res 2010;71:161-167.

27 Savage DB, Choi CS, Samuel VT, Liu ZX, Zhang D, Wang A, Zhang XM, Cline GW, Yu XX, Geisler JG, Bhanot S, Monia BP, Shulman GI: Reversal of diet-induced hepatic steatosis and hepatic insulin resistance by antisense oligonucleotide inhibitors of acetyl-coa carboxylases 1 and 2. J Clin Invest 2006;116:817-824.

28 Hwang JH, Perseghin G, Rothman DL, Cline GW, Magnusson I, Petersen KF, Shulman GI: Impaired net hepatic glycogen synthesis in insulin-dependent diabetic subjects during mixed meal ingestion. A 13c nuclear magnetic resonance spectroscopy study. J Clin Invest 1995;95:783-787.

29 Vickers MH, Breier BH, Cutfield WS, Hofman PL, Gluckman PD: Fetal origins of hyperphagia, obesity, and hypertension and postnatal amplification by hypercaloric nutrition. Am J Physiol Endocrinol Metab 2000;279:E83-87.

-30 Almeida JR, Mandarim-de-Lacerda CA: Maternal gestational protein-calorie restriction decreases the number of glomeruli and causes glomerular hypertrophy in adult hypertensive rats. Am J Obstet Gynecol 2005;192:945-951.

31 Sun K, Kusminski CM, Scherer PE: Adipose tissue remodeling and obesity. J Clin Invest 2011;121:20942101.

32 Garcia AP, Palou M, Sanchez J, Priego T, Palou A, Pico C: Moderate caloric restriction during gestation in rats alters adipose tissue sympathetic innervation and later adiposity in offspring. PLoS One 2011;6:e17313.

-33 Shoelson SE, Lee J, Goldfine AB: Inflammation and insulin resistance. J Clin Invest 2006;116:1793-1801.

34 Tomita M, Yamamoto K, Kobashi H, Ohmoto M, Tsuji T: Immunohistochemical phenotyping of liver macrophages in normal and diseased human liver. Hepatology 1994;20:317-325. 